\title{
DEDICATION
}

\section{Norman E. McSwain Jr., MD, FACS (1937-2015)}

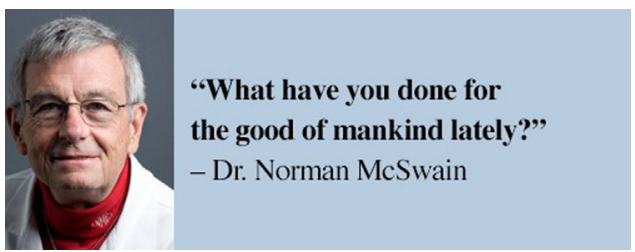

This special edition of Wilderness \& Environmental Medicine, Tactical Combat Casualty Care: Transitioning Battlefield Lessons Learned to Other Austere Environments is dedicated to Norman E. McSwain Jr., MD, FACS (1937-2015). Trauma Surgeon

Professor, Department of Surgery, Tulane University School of Medicine

Founder, Editor-in-Chief, Prehospital Trauma Life Support Founding Member, Committee on Tactical Combat Casualty Care (2001-2015)

Internationally renowned and respected for his pioneering work in trauma care, Dr. McSwain founded the National Association of Emergency Medical Technicians (NAEMT)'s Prehospital Trauma Life Support (PHTLS) program 30 years ago and is recognized by NAEMT as the father of NAEMT education. Dr. McSwain was a founding member of the Committee on Tactical Combat Casualty Care (CoTCCC) and was a great friend, colleague, and mentor. His efforts in 1998 and 1999 initially forged the link between PHTLS and Tactical Combat Casualty Care (TCCC). He was the codesigner of the CoTCCC logo in 2008 (Figure). The inclusion of "prehospital life support" in the logo highlights the ongoing partnership between PHTLS and TCCC that has contributed greatly to the group's efforts to improve the care for our country's wounded servicemen and servicewomen. Norman graciously donated many hundreds of hours of his time to help make possible the advances that TCCC has pioneered. More than that, he befriended the entire CoTCCC group as only he could do.

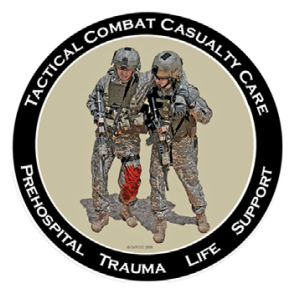

Figure. Committee on Tactical Combat Casualty Care (CoTCCC) logo, codesigned by Norman E. McSwain Jr., MD in 2008.
In addition to his prestigious career as a trauma surgeon, Dr. McSwain was a certified paramedic. He worked tirelessly throughout his career to ensure that emergency medical systems (EMS) practitioners, both in the civilian and military sectors, received the highest quality education to enable them to provide the best care to their patients. He understood the important role of paramedicine in improving patient survivability in a trauma incident and made it part of his life's mission to provide all EMS practitioners with the knowledge and skills needed to make good decisions in the field for their patients.

Within the last year of his life, he was a key member of the Hartford Consensus Working Group and the National Academies of Sciences, Engineering, and Medicine committee, devoted to helping to translate military advances in prehospital trauma care to the civilian sector to enable the nation to better care for millions of injured civilians. His message rings clearly through these important efforts. He was a passionate supporter of effective trauma systems: early hemorrhage control by immediate bystanders, integrated into timely, expert EMS and police response, and rapid transfer to a center where expert trauma care can be delivered. Dr. McSwain's commitment in these areas has direct application to wilderness medicine.

Norman was also a huge personality with a classic southern gentlemen demeanor. He lit up the room when he walked in, and you felt his presence before you even saw him. He was famous for his humor and ready smile as he greeted all warmly, even those he did not know. Norman is survived by the many members of his immediate family, the members of the CoTCCC, and his worldwide trauma medicine family. Norman was an inspiration to all and is greatly missed.

\section{CAPT (Ret.) Brad L. Bennett, PhD, EMT-P, FAWM Bena, VA}

CAPT (Ret.) Frank K. Butler Jr., MD, FAAO, FUHM Pensacola, FL

COL Ian S. Wedmore, MD, FAWM Tacoma, WA 